EDITORIAL

\title{
Sudden arrhythmic death syndrome
}

\author{
Bruce A Koplan, William G Stevenson
}

See article on page 601

S udden death is a major source of mortality in developed countries. Identifying patients at risk and implementing treatment for prevention requires an understanding of the causes.

Ventricular arrhythmias precipitating cardiac arrest are the most common mechanisms of sudden death. Virtually any cardiac disease and a number of non-cardiac diseases can lead to the fatal sequence of events; coronary artery disease is the single most common underlying disease. Approximately half of all deaths from coronary artery disease occur suddenly, and in approximately half of these victims cardiac arrest is the first manifestation of the disease. ${ }^{1}$ Although this scenario accounts for the largest group of sudden deaths, the risk to a single individual in the huge population of people with asymptomatic or mildly symptomatic coronary artery disease is very small, such that specific treatment that targets arrhythmias is not warranted. The individual risk of sudden death increases, however, once evidence of structural heart disease, particularly with depressed ventricular function, develops. A large number of studies have shown that, on the basis of the severity of structural heart disease, patient groups with a risk of sudden death exceeding 2-5\% per year can be identified, and that treatment ranging from $\beta$ adrenergic blockers and ACE inhibitors to, in the highest-risk group, implantable cardioverter defibrillators, can reduce mortality from sudden death with acceptable benefit.

Over the past two decades, a large number of inherited arrhythmogenic syndromes that cause sudden death have been characterised. Some are associated with structural heart disease, such as hypertrophic cardiomyopathy and arrhythmogenic right ventricular cardiomyopathy. Others do not produce structural heart disease. Most are due to inherited abnormalites of cardiac ion channels, such as the long QT syndrome, short QT syndrome, familial catecholaminergic polymorphic ventricular tachycardia and Brugada syndrome. ${ }^{1}$ Many of these syndromes can be identified or suspected from a resting ECG or exercise test, but individually they are rare, and not commonly sought in routine health examinations The only symptoms that affected individuals' experience are due to arrhythmias, such that the first manifestation of the disease is often cardiac arrest from polymorphic ventricular tachycardia degenerating to ventricular fibrillation and sudden death. Some affected individuals are more fortunate, experiencing non-sustained arrhythmias, presenting as palpitations or syncope, leading to recognition of the disease and treatment. Other affected but asymptomatic or undiagnosed individuals are identified when a family member dies suddenly, and the possibility of a genetic abnormality is considered, leading to screening of the victim's relatives. Unfortunately, a postmortem examination of the victim does not suggest the specific cause, and, all too frequently, the possibility of an inherited sudden death syndrome is not considered, or family members are not informed of the possibility when the autopsy is unrevealing.

Victims of sudden death from these diseases fall under the rubrick of sudden adult death syndrome (SADS), which has been coined to describe sudden death without a structural cause identified by autopsy or toxicological examination. ${ }^{2}$ Previous studies from the UK and the US estimated that $>4 \%$ of sudden cardiac deaths fall into this category. Importantly, when screened, $>20 \%$ of the first-degree relatives of SADS victims are found to have some form of inherited arrhythmogenic disease. ${ }^{3-5}$ The demographics of SADS have not been well defined and there is a need for uniform terminology and data collection to understand better the importance of these diseases and how they might be better recognised. ${ }^{6}$

In this issue of Heart, Behr et al estimate mortality due to SADS from mortality statistics and a prospective survey of coroners' evaluations from 117 jurisdictions in England. The coroners' evaluation was extensive and included assessment of expert cardiac pathologists and home interviews of next of kin. The authors derive an estimated annual mortality of $0.16 / 100000$ people per year. This is substantially greater than that expected from the official ICD 798.1 category of sudden death (cause unknown-instantaneous death) of 0.10/100 000 people per year. Furthermore, they calculate that the number of potential SADS cases, on the basis of all ICD codes to which SADS could be assigned, is $1.34 / 100000$, a rate that is $>8$ times greater than the survey's estimate.

Interestingly, a significant number of cases determined to be SADS had been incorrectly labelled with diagnoses such as myocardial infarction. This observation is consistent with the familiar description by family members, years after the event, that death was due to a massive heart attack. This description may satisfy the family as to cause, but in SADS cases obscures the possibility of an inherited syndrome that requires assessment and possibly treatment. The importance of this consideration is emphasised by the finding that $18 \%$ of SADS cases were associated with a family

Abbreviation: SADS, sudden adult death syndrome 
history of other premature sudden deaths, supporting the possible existence of an inherited arrhythmogenic syndrome, and consistent with prior investigations. ${ }^{8}$ The author's contention that SADS is underestimated in the population seems likely.

As in some previous reports, this study found that SADS is more common in men (63\% of cases)..$^{9}{ }^{10}$ The reasons for this predisposition are not clear. Men are disproportionately affected in Brugada syndrome, and the risk of sudden death is greater for men with some forms of the long QT syndrome. ${ }^{11}$ Thus, a male predominance might reflect the prevalence of some specific causes of sudden death syndromes.

There are limitations to these data. Only Caucasians were included. SADS event rates and demographics may be different in other ethnic groups and in other countries. Not all deaths in the coroners' counties may have received the extensive evaluation required by the study, such that even this study may underestimate the incidence of SADS. Is it possible that focal abnormalities such as small regions of fibrosis or myocarditis escaped detection in some victims? ${ }^{12}$ On the other hand, myocardial fibrosis has been reported in Brugada syndrome, illustrating that some inherited ion channel abnormalities may be associated with structural changes; and refinement of definitions will probably be required as the entities causing SADS continue to be better characterised.

Population studies of the demographics of sudden death are dominated by the effect of coronary artery disease. The epidemiology of sudden death in the absence of ischaemic heart disease is not as well defined, in part, because autopsies are not routinely performed in many countries and an assumption is often made that coronary disease was the cause of death. The study by Behr et $a l^{7}$ is the first prospectively and uniformly to require coroners to apply a postmortem diagnosis of SADS, a unique subset of sudden death. This study builds on earlier work by the same group that developed a definition of "SADS". ${ }^{13}$ With the current data and increasing recognition of arrhythmogenic syndromes, they now suggest that SADS should be replaced by "sudden arrhythmic death syndrome", recognising that children and adolescents are also affected, and emphasising the mechanism of arrhythmia. Uniform adoption of this explicit definition for reporting will help clarify the importance of inherited syndromes as a cause of sudden death and facilitate epidemiological investigations of existing and newly recognised syndromes, an awareness that will foster greater consistency in the screening of family members of SADS victims and save lives.

\section{Authors' affiliations}

Bruce A Koplan, William G Stevenson, The Cardiovascular Division, Brigham and Women's Hospital, Harvard Medical School, Boston, Massachusetts, USA

Competing interests: None declared.

\section{REFERENCES}

1 ACC/AHA/ESC. ACC/AHA/ESC 2006 Guidelines for management of patients with ventricular arrhythmias and the prevention of sudden cardiac deathexecutive summary: a report of the American College of Cardiology/American Heart Association Task Force and the European Society of Cardiology Committee for Practice Guidelines (Writing Committee to Develop Guidelines for Management of Patients With Ventricular Arrhythmias and the Prevention of Sudden Cardiac Death): developed in collaboration with the European Heart Rhythm Association and the Heart Rhythm Society. Circulation 2006;114:1088-132.

2 Bowker TJ, Wood DA, Davies MJ, et al. Sudden, unexpected cardiac or unexplained death in England: a national survey. QJM 2003;96:269-79.

3 Behr E, Wood DA, Wright $M$, et al. Cardiological assessment of first-degree relatives in sudden arrhythmic death syndrome [comment]. Lancet 2003;362:1457-9.
4 Shen WK, Edwards WD, Hammill SC. Sudden unexpected nontraumatic death in 54 young adults: a 30-year population-based study. Am J Cardiol 1995;76:148-52.

5 Drory $Y$, Turetz $Y$, Hiss $Y$, et al. Sudden unexpected death in persons less than 40 years of age. Am J Cardiol 1991;68:1388-92.

6 Davies MJ. Unexplained death in fit young people [comment]. BMJ 1992;305:538-9.

7 Behr ER, Casey A, Sheppard M, et al. Sudden arrhythmic death syndrome: a national survey of sudden unexplained cardiac death. Heart 2007;93:601-5.

8 Tan HL, Hofman N, van Langen IM, et al. Sudden unexplained death: heritability and diagnostic yield of cardiological and genetic examination in surviving relatives. Circulation 2005;112:207-13.

9 Tamakoshi K, Toyoshima H, Yatsuya H. Gender difference of sudden death. Nippon Rinsho-Jpn J Clin Med 2005;63:1284-8.

10 Fabre A, Sheppard MN. Sudden adult death syndrome and other non-ischaemic causes of sudden cardiac death. Heart 2006:92:316-20.

11 Hobbs JB, Peterson DR, Moss AJ. Risk of aborted cardiac arrest or sudden cardiac death during adolescence in the long-QT syndrome. JAMA 2006;296: 1249-54.

12 Corrado D, Basso C, Thiene G. Sudden cardiac death in young people with apparently normal heart. Cardiovasc Res 2001:50:399-408.

13 Bowker TJ, Wood DA, Davies MJ. Sudden unexpected cardiac death: methods and results of a national pilot survey. Int J Cardiol 1995;52:241-50.

\section{WEB TOP 10}

www.heartinl.com

These articles scored the most hits on Heart's website during February 2007

1 The value of risk scores

JS Jürgensen

December 2006;92:1713-4. (Editorial)

2 JBS 2: Joint British Societies' guidelines on prevention of cardiovascular disease in clinical practice

December 2005;91(suppl V):1-52. (Supplement)

3 Intervention in acute coronary syndromes: do patients undergo intervention on the basis of their risk characteristics? The Global Registry of Acute Coronary Events (GRACE) KAA Fox, FA Anderson, OH Dabbous, PG Steg, J López-Sendón, $F$ Van de Werf, A Budaj, E P Gurfinkel, SG Goodman, D Brieger, on behalf of the GRACE investigators

February 2007;93:177-82. (Acute coronary syndromes)

4 Antiplatelet treatment for coronary heart disease

N Clappers, MA Brouwer, FWA Verheugt

February 2007;93:258-65. (Education in Heart)

5 Heart failure with a normal ejection fraction

JE Sanderson

February 2007;93:155-8. (Heart review)

6 Drug induced QT prolongation and torsades de pointes

YG Yap, AJ Camm

November 2003;89:1363-72. (Education in Heart)

7 Diagnosis and management of patients with aortic dissection $H$ Ince, CA Nienaber

February 2007;93:266-70. (Education in Heart)

8 Management of tricuspid valve regurgitation

MJ Antunes, JB Barlow

February 2007;93:271-6. (Education in Heart)

9 Underuse of revascularisation in acute coronary syndromes

F-J Neumann, HJ Büttner

February 2007;93:147-8. (Editorial)

10 Cardiovascular, cerebrovascular, and respiratory changes induced by different types of music in musicians and nonmusicians: the importance of silence

L Bernardi, C Porta, P Sleight

April 2006;92:445-2. (Cardiovascular medicine)

Visit the Heart website for hyperlinks to these articles, by clicking on "Top 10 papers"

www.heartinl.com 